\title{
Harmonic Research and Mitigation Techniques in Induction Furnace
}

\author{
D.Rajalakshmi, R.Kavitha, K.Premalatha
}

\begin{abstract}
Induction furnaces are widely applied for heating and melting purpose in Iron and steel industries. Induction furnace injects significant amount of harmonics when operated under varying load conditions.This leads to power loss and affects the performance of adjacent loads. The aim of the paper is to analyze the harmonic profile of induction furnace in steel industry and suggest solution to mitigate the harmonics using a Unified Power Quality Conditioner (UPQC). The experimental voltage and current harmonics of the induction furnace are analyzed using power quality logger for a steel industry. From the experimental analysis, simulation is performed in MATLAB/SIMULINK and solutions are presented to mitigate the harmonics using UPQC.
\end{abstract}

Keywords - Induction furnace, UPQC, Harmonics, THD

\section{INTRODUCTION}

Power quality is defined as occurrence of problem/fluctuations in voltage, current or frequency that results in failure or mal-operation of electric equipment. Power quality events seriously destroy industrial infrastructure and are largely untracked [1]. Industrial requirements regarding power quality issues are discussed in [2]. The usage of nonlinear loads like arc or ladle furnaces in heavy-industry plants, power converters, results in distortion in waveforms of current and voltage. The voltage and current distortion comprises of harmonics that are multiples of fundamental frequency. International Electrotechnical Commission (IEC) and IEEE have specified standards for limits of harmonic emission [3]-[5]. Optimized Harmonic minimization techniques for mitigating harmonics is presented in [6-7]. The induction furnace plays a vital role in the operation of steel industries and are nonlinear in nature. Induction furnace injects significant harmonics when operated under varying load conditions[8]. Voltage distortions in induction furnace are measured and voltage waveform distortion model is presented in [9]. Many of steel melting industries equipped with Induction furnace are having 2-pulse or 24-pulse phase controlled circuits .

\section{METHODOLOGY}

The power circuit diagram of induction furnace employed in steel industry is shown in fig.1. The AC supply is converted into DC by fully controlled rectifier and constant DC is achieved by DC link inductor. The induction heating requires high frequency and thus six pulse current source

D.Rajalakshmi, Associate Professor,Department of Electrical and Electronics Engineering, Kumaraguru College of Technology Coimbatore, T.N. India. (rajalakshmi.d.eee@kct.ac.in)

R.Kavitha, Associate Professor,Department of Electrical and Electronics Engineering, Kumaraguru College of Technology Coimbatore, T.N. India (kavitha.r.eee@kct.ac.in)

K.Premalatha, Associate Professor,Department of Electrical and Electronics Engineering, Kumaraguru College of Technology, Coimbatore, T.N. India (premalatha.k.eee@kct.ac.in)
Revised Manuscript Received on August 14, 2019.

inverter is employed to convert $\mathrm{DC}$ into high frequency $\mathrm{AC}$ and is connected to Induction furnace coil by coupling capacitor bank. 12-pulse rectifiers are preferred and it has two three phase bridge, the supply to individual bridge is fed by using phase shifting transformers. With increase in number of pulse, the output line current becomes approximated sinusoidal waveform and results in reduction of current distortion. The rating of the furnace employed for field measurement is presented in Table .1

Table 1 : Rating of the furnace

\begin{tabular}{|l|l|}
\hline Type & Coreless Induction furnace \\
\hline Power rating & $450 \mathrm{~kW}$ \\
\hline Voltage & $415 \mathrm{~V}$ \\
\hline Capacity & $1000 \mathrm{Kg}$ \\
\hline
\end{tabular}

Active filters are preferred instead of passive filter for eliminating power quality problems. Key Power quality problems like harmonics and sag are mitigated using UPQC. Instantaneous elimination of current and voltage problems are achieved by shunt and series active filter. The power fed is linked through common DC link and maintains constant real power exchange [10-12]. This paper presents experimental results of field survey conducted in an induction furnace applied in steel industry. The voltage and current harmonics are analyzed and solutions for harmonic reduction is discussed using UPQC.

\section{FIELD MEASUREMENT OF HARMONICS IN INDUCTION FURNACE}

The Field measurement is taken for an induction furnace employed in steel industry and its ratings is indicated in Table 1. The voltage and current waveforms are shown in fig.2 (a) .The voltage harmonics of the three phases are shown in fig 2(b)-(d). It is observed that current waveform is highly distorted when compared to voltage waveform . The current harmonics generated in an induction furnace is measured by power logger and shown in fig 3 . The lower order harmonics are higher and THD value of $25 \%$ indicates larger amount of current harmonics in the supply. The $\mathrm{k}$-factor indicates the measure of transformer overheating due to existence of harmonics and its value is $4.09 \%$

Published By: 


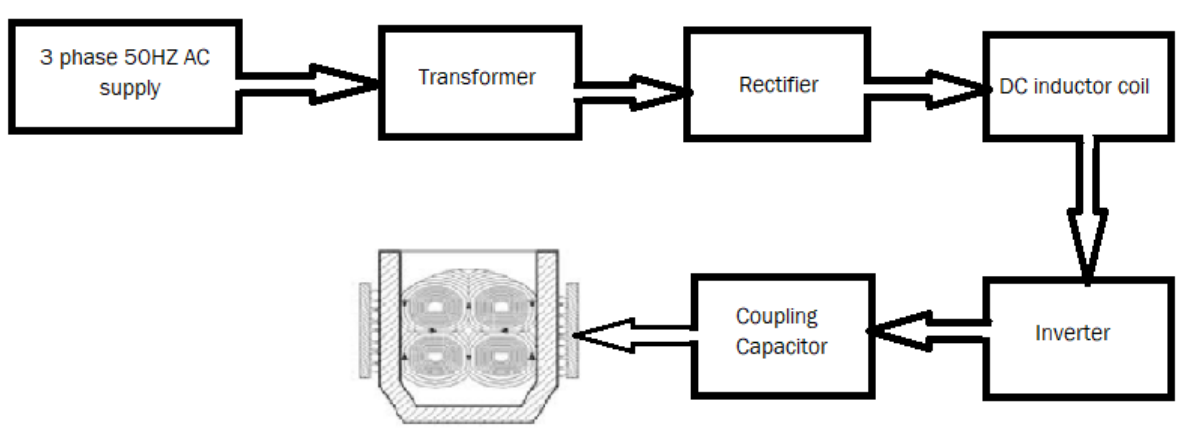

Fig.1. Power Circuit of Induction furnace

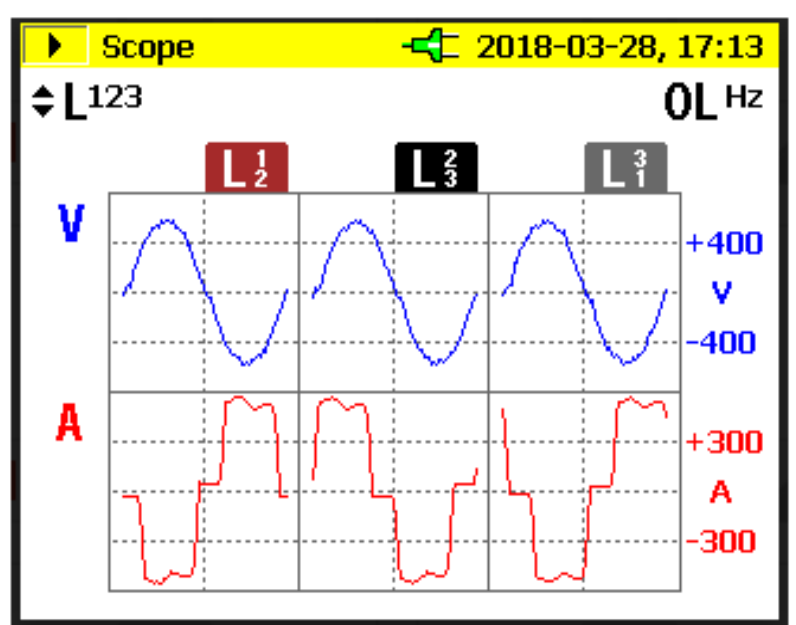

(a)
Harmonics -50 2018-03-28, 16:59

$\rightarrow L_{1}^{3}$ THD $\quad 4.6 \%$

Vrms $417.7 \mathrm{~V}$

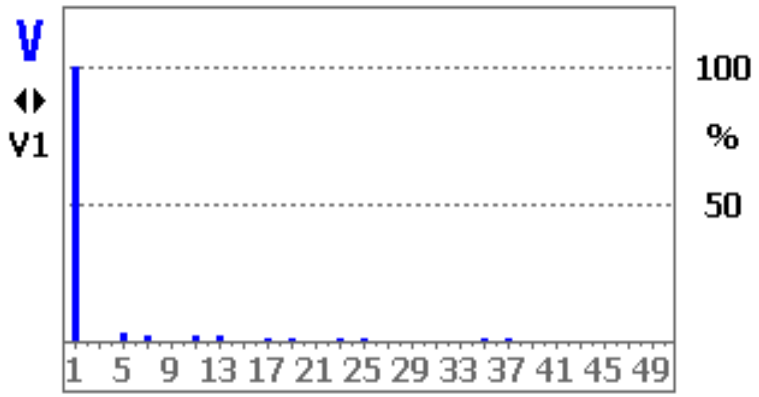

(b)

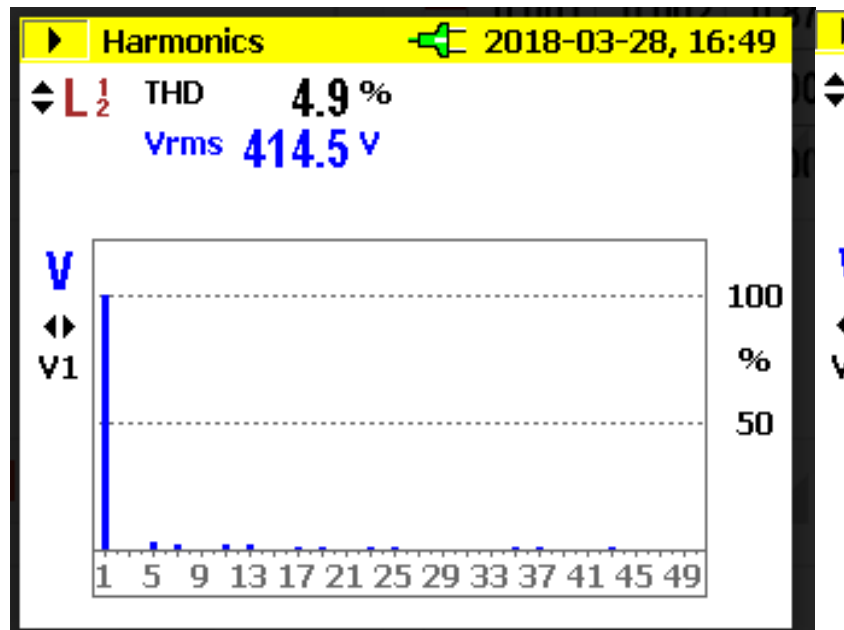

(c)
- Harmonics

$\because L_{3}$ THD $\quad 4.7 \%$

Vrms $415.4^{v}$

-5f 2018-03-28, 16:59

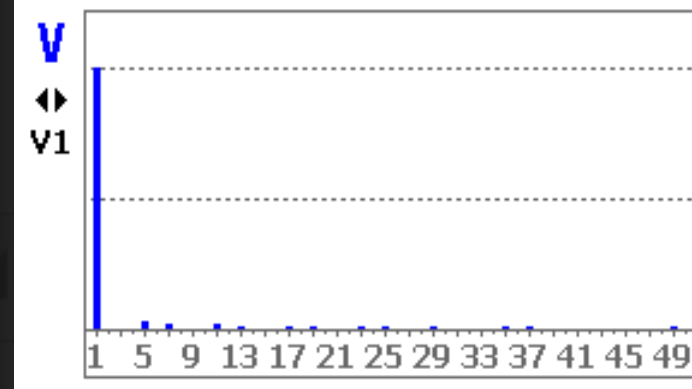
100 $\%$ 50

(d)

Fig.2. : (a) voltage and current waveform (b) Harmonic profile of line voltage $V_{13}$ (c) Harmonic profile of line voltage $V L_{12}$ (d) Harmonic profile of line voltage $V L_{23}$

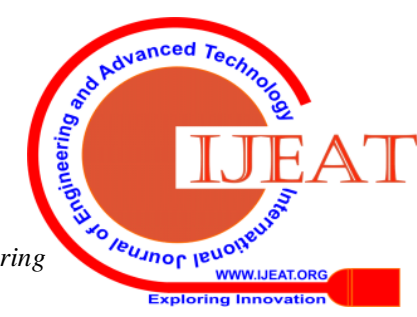




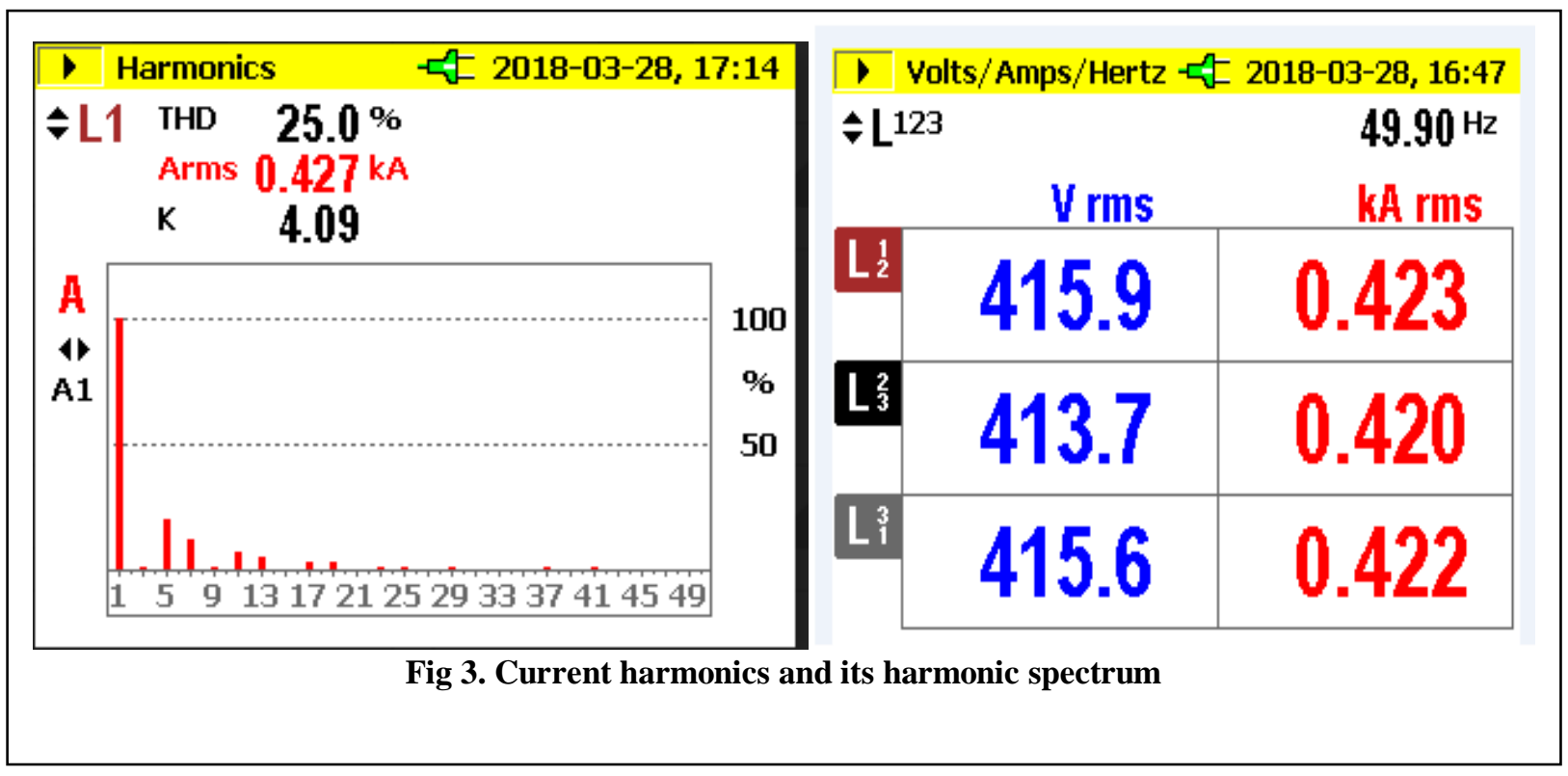

Based on the measurement it is observed that THD is low during initial phase and then it increases as loading of scrap is performed. The individual harmonic percentage obtained during field study is indicated in Table.2. The Simulink model of power circuit with induction furnace is done using MATLAB Simulink software. The firing angle for the phase controlled converter is provided by employing discrete pulses. The frequency of the output is increased from $50 \mathrm{~Hz}$ to $600 \mathrm{~Hz}$ and fed to induction furnace unit.

\section{UPQC FOR HARMONIC MITIGATION AND ITS SIMULATION RESULTS}

UPQC consists of series and shunt active filter. The series inverter is practiced for moderating voltage related harmonics and shunt inverter for moderating current related harmonics. The compensation voltage Injected by the series inverter is found to be the sum of source voltage and compensated voltage. The series voltage injected at the required magnitude and phase angle and this result in the regulation of rated sinusoidal voltage in the load bus. The voltage related power quality problems such as voltage sag, swell, imbalance, flicker harmonics are avoided. Series inverter absorb or supply real power in addition to the reactive power and this phase angle of injected voltage varies from 0 to $360^{\circ}$.

Table 2 Individual Current harmonics and THD

\begin{tabular}{|l|l|l|l|l|l|l|}
\hline $\begin{array}{l}\text { Harmonic } \\
\text { order }\end{array}$ & $5^{\text {th }}$ & $7^{\text {th }}$ & $11^{\text {th }}$ & $13^{\text {th }}$ & $17^{\text {th }}$ & $19^{\text {th }}$ \\
\hline $\begin{array}{c}\text { Amplitude of } \\
\text { harmonics } \\
\text { (as a \% of } \\
\text { fundamental) }\end{array}$ & 19.3 & 12.9 & 4.1 & 2.9 & 1.2 & 1 \\
\hline
\end{tabular}

The shunt inverter has the ability to regulate the DC link voltage and to compensate the current related power quality issues such as harmonics, interharmonics, reactive power requirements. The compensation capability of both inverters is realized by means of a proper control. Shunt inverter supplies or absorbs the reactive power provided by the series inverter. In this paper, Unified power quality conditioner (UPQC) for Induction furnace and it mitigates the harmonics in the supply current and improves the current quality. UPQC also provides in phase supply voltage and current and thus extra power factor improvement device is not required. Open loop system is modelled using MATLAB for non lineaer load. The UPQC is modelled in MATLAB Simulink and shown in fig 5

The simulated waveforms of current and voltage, and their corresponding harmonic profile are shown in fig.6 9. The simulated open loop system specifications are in correlation with the induction furnace where field study is made. The simulated sytem input voltage is $440 \mathrm{~V}, 50$ $\mathrm{HZ}$ and the non linear load is added which is equivalent to induction furnace. Fig 6 and 7 shows the voltage waveform, current waveform and its harmonic spectrum without UPQC (open loop system). Voltage THD is 4.2 $\%$ and current THD is $25.2 \%$. Individual current harmonics are varying from $0.3 \%$ to $19 \%$ more or less matching with induction furnace data taken in previously mentioned industry.

Fig 8 and 9 shows the result produced by the system with UPQC. Voltage THD is reduced from $4.1 \%$ into $0.09 \%$ when it is measured with UPQC. The Voltage THD is reduced more than $3 \%$. The current THD is $7.1 \%$ with UPQC. When compared to system with out UPQC , it is reduced more than $18 \%$. The lower order harmonics $\mathrm{h} 5$ is $8 \%$ and $\mathrm{h} 7$ is $4 \%$ when UPQC is employed which inturn minimizes the source current distortion. The proposed UPQC for Induction furnace shows the better performance then the system without UPQC. 


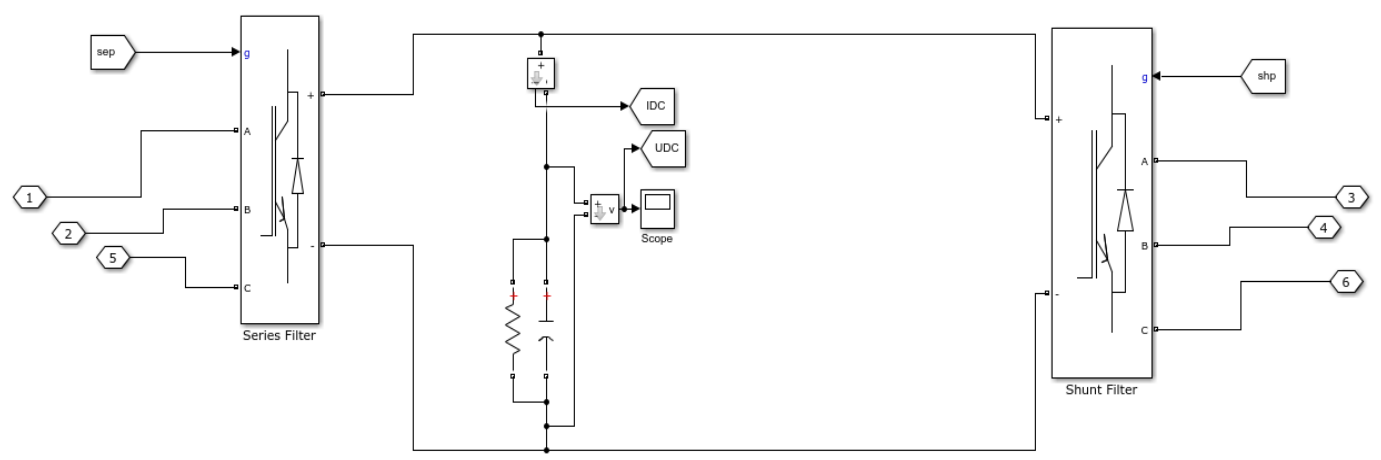

Fig 5. UPQC model

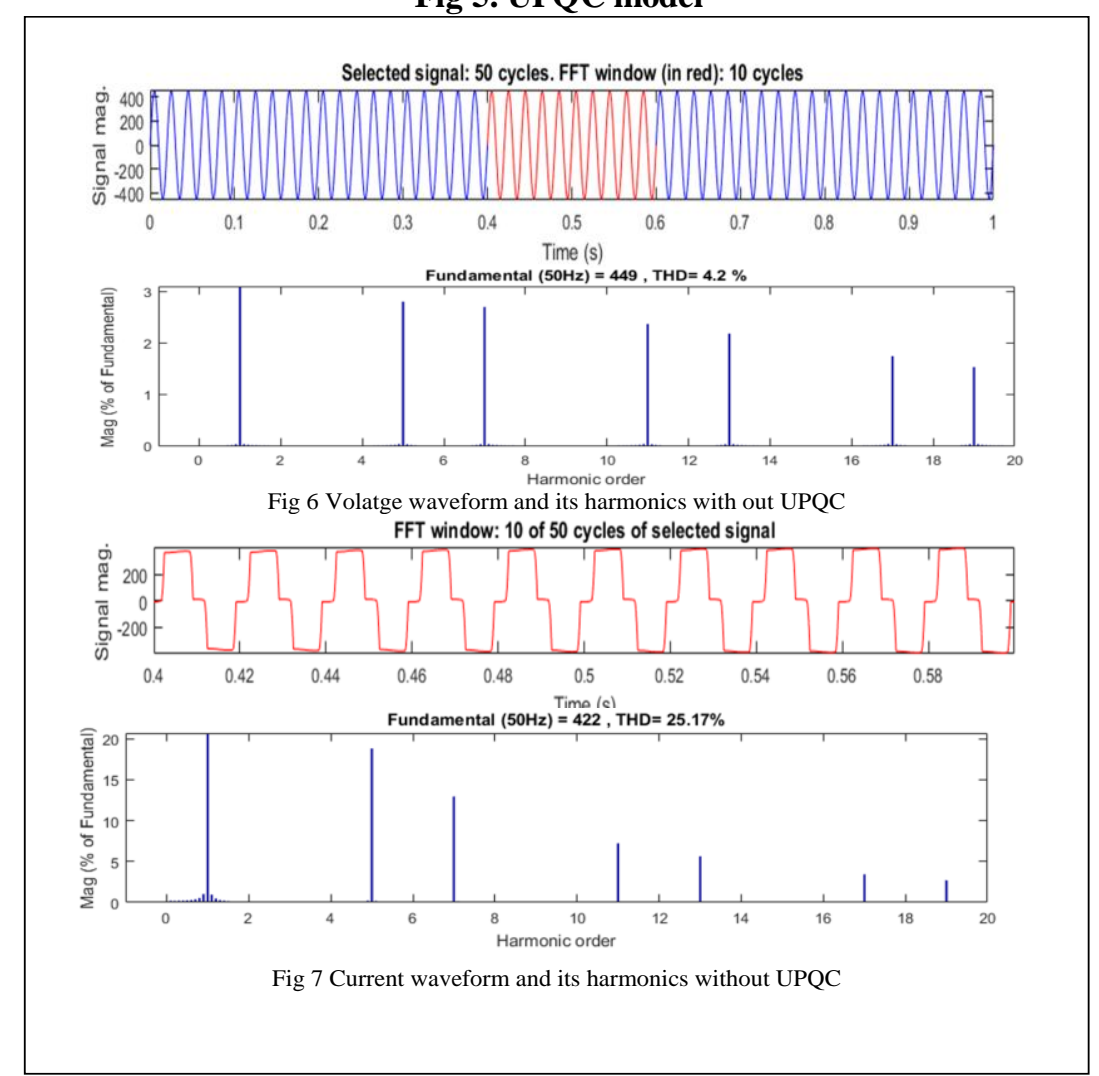




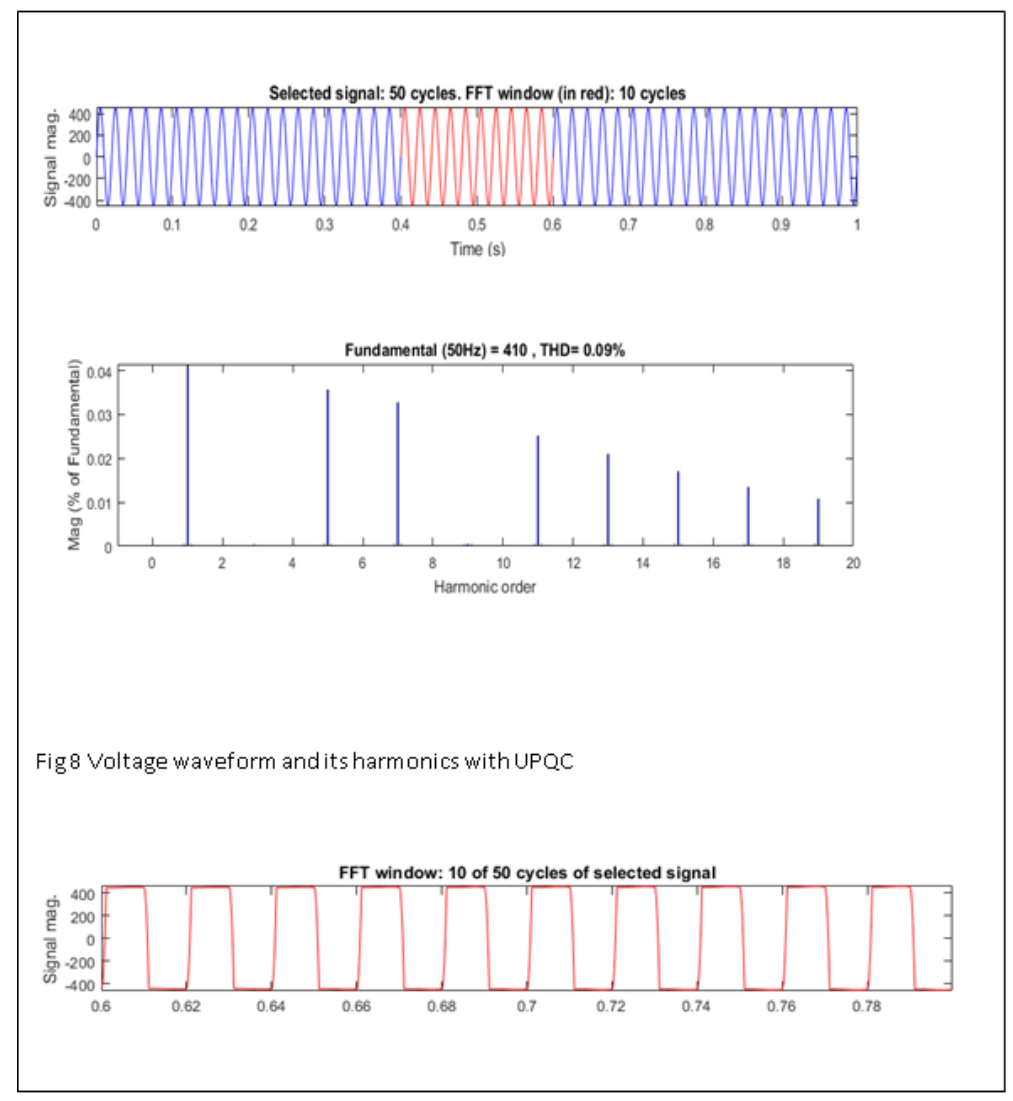

\section{CONCLUSION}

In the steel industries employing an induction furnace, the power quality is essentially dependent upon the harmonics present in the system. From the field measurement carried out in a induction furnace used in steel industry it is inferred that the voltage harmonics is $4.9 \%$ and current harmonics is $25.0 \%$. Also the lower order harmonics are higher (h5 -19.3\% h7- 12.7\%). Simulink analysis is performed based on the same parameters employed in field study. UPQC with induction furnace as non linear load is simulated in MATLAB/SIMULINK. It is inferred that voltage harmonics is reduced to $0.9 \%$ and current harmonics reduced $7.1 \%$. The study can further be exploited for different type and rating of induction furnace . Further different novel topologies of inverter can be studied for reducing source current distortion.

\section{REFERENCES}

1. Mohd Izhwan Muhamad, Norman Mariun " The Effects Of Power Quality To The Industries", The 5th Student Conference on Research and Development -SCOReD 2007 11-12 December 2007, Malaysia.

2. Shih An Yin, Chan Nan Lu, Edwin Liu, Yu Chang Huang, Chinug Yi Huang, "A Survey on High Tech Industry Power Quality Requirements", IEEE, 2001.

3. Recommended Practices and Requirements for Harmonic Control in Electrical Power Systems, IEEE Std. 519-1992, 1992.

4. Testing and Measurement Techniques-Power Quality Measurement Methods, IEC 61000-4-30, 2003.

5. Testing and Measurement Techniques-General Guide on Harmonics and Interharmonics Measurements and Instrumentation, for Power Supply Systems and Equipment Connected Thereto, IEC 61000-4-7, 2003.

6. Rajalakshmi.D., Geetha.K.,Malathi .M., (2014, February) . Odd and Even Switching Pattern in PV Generation System Coupled
SHEPWM Inverter to Reduce Harmonics in Grid. International Journal of Emerging Technology and Advanced Engineering , 4(2) ,105-109.

7. Kavitha .R., Thottungal.R., (2018) Reconfigurable Selective Harmonic Elimination Technique for Wide Range Operations in Asymmetric Cascaded Multilevel Inverter. Journal of Power Electronics,18(4), 1037-1050.

8. Arunkumar, R., and Nagaraj Balakrishnan. "Medical image classification for disease diagnosis by DBN methods." Pak J Biotechnol 15, no. 1 (2018): 107-110.

9. Saggu, T. S., Singh, L., Gill, B., \& Malik, O. P. (2018), Effectiveness of UPQC in Mitigating Harmonics Generated by an Induction Furnace. Electric Power Components and Systems, 46(6), 629-636.

10. Yılmaz, İ., Durna, E., \& Ermiș, M. (2016). Design and implementation of a hybrid system for the mitigation of $\mathrm{PQ}$ problems of medium-frequency induction steel-melting furnaces. IEEE Transactions on Industry Applications, 52(3), 2700-2713.

11. Khadkikar, V. (2011). Enhancing electric power quality using UPQC: A comprehensive overview. IEEE transactions on Power Electronics, 27(5), 2284-2297.

12. Zadeh, F. H., \& Naseh, M. R. (2014). Power quality improvement in distributed generation resources using UPQC. International Journal of Renewable Energy Research (IJRER), 4(3), 795-800.

13. Iagăr, A., Popa, G. N., \& Diniş, C. M. (2019, March). Experimental Analysis of a High-Frequency Induction Furnace and its Impact on Power Quality. In 2019 11th International Symposium on Advanced Topics in Electrical Engineering (ATEE) (pp. 1-6). IEEE. 